\title{
Inter- and intraspecific heterochromatin variation detected by restriction endonuclease digestion in two sibling species of the Anopheles maculipennis complex
}

\author{
Annalisa Marchi and \\ Roberto Mezzanotte
}

Istituto di Biologia Generale, Facoltà di Medicina e Chirurgia, Università di Cagliari, Via Ospedale 119, 09124 Cagliari, Sardinia, Italy.

The sibling species Anopheles atroparvus and Anopheles labranchiae are cytogenetically almost indistinguishable. The chromosome complement $(2 n=6)$ consists of two pairs of autosomes and two heteromorphic sex chromosomes with largely homologous heterochromatic long arms. Treatment of chromosome preparations with the restriction endonucleases, Alu I, Hae III, Mbo I, Hpa II, revealed species-specific differences of the sex chromosome banding pattern. These differences involved both amount and location of digested heterochromatin. Heterochromatin heterogeneity and a high level of intraspecific polymorphism, undetected with standard banding techniques, were observed in both species. Quantitative heterochromatin differences between the sex chromosomes did not inhibit their pairing and chiasmata formation. The endonuclease Msp I, which cleaves the same target sequence as Hpa II, did not digest heterochromatic as well as euchromatic regions in both species: inhibition of cleavage by methylation of the target sequence or limited access of the enzyme to the target could be involved in this response.

\section{INTRODUCTION}

The human malaria vectors Anopheles labranchiae Falleroni and Anopheles atroparvus Van Thiel (Diptera: Culicidae) are morphologically and genetically the most closely related species of the palaearctic Anopheles maculipennis group (Diptera: Culicidae). These sibling species are cytogenetically almost indistinguishable. The salivary gland polytene chromosomes are homosequential (Frizzi 1947; Kitzmiller et al., 1967), although asynchronous replication of homologous bands has been observed in interspecific hybrids (Tiepolo et al., 1974). The chromosome complement consists of two pairs of autosomes and two heteromorphic sex chromosomes. The karyotypes of the two species are comparable in terms of morphology, total chromosome length and DNA content (Jost and Mameli, 1972). The $\mathrm{X}$ and $\mathrm{Y}$ chromosomes (submetacentric and subtelocentric respectively) have largely homologous heterochromatic, late replicating, long arms and form chiasmata in meiosis (Fraccaro et al., 1976; Jayakar et al., 1982; Marchi, personal observation). $\mathrm{C}$-positive heterochromatin is similarly distributed in $A$. atroparvus and A. labranchiae (Mezzanotte and Ferrucci, 1978), although qualitative differences of heterochromatin DNA between the two species have been inferred using fluorescent banding techniques (Mezzanotte and Ferrucci, 1978; Mezzanotte et al., 1979).

Restriction endonucleases (RE) have been used on fixed chromosomes in situ to discriminate between regions with different distribution and frequency of RE cleavage sequences, i.e., with different DNA composition (Mezzanotte et al., 1983; Miller et al., 1983). This technique has already provided new insight on the chromatin organization and DNA composition of various insect groups (Mezzanotte, 1986; Bianchi et al., 1986; Bultmann and Mezzanotte, 1987; Gozalvez et al., 1987; Mezzanotte and Marchi, 1987; LopezFernandez et al., 1988; Marchi and Mezzanotte, 1988). With the aim of revealing further chromatin/DNA differences between $A$. atroparvus and $A$. labranchiae, we tested five REs on the chromosomes of these closely related species. A large amount of heterochromatin resistant to RE digestion was present in both species. However, species-specific differences of RE banding patterns 
were detected. A high level of intraspecific polymorphism, in many cases undetected with other banding methods and involving different types of constitutive heterochromatin, was also observed.

\section{MATERIAL AND METHODS}

Immature stages of $A$. labranchiae were collected from south-eastern Sardinia. A. atroparvus specimens were from a laboratory colony maintained at the Genetics Institute, University of Cagliari, Sardinia, for many years. Cephalic ganglia and gonads were dissected from IV instar larvae and pupae and fixed in methanol: acetic acid $(3: 1)$ for $30 \mathrm{~s}$, transferred to $45-60$ per cent acetic acid and squashed under a siliconized coverslip. Air dried slides were stored at $4^{\circ} \mathrm{C}$ for one day before processing. The following restriction enzymes were tested: Alu I, Mbo I, Hae III, Hpa II and Msp I (Boehringer, FDR, and New England Labs., U.K.). Twenty units of the enzyme were diluted in Tris-saline buffer (Maniatis et al., 1982) to a final volume of $100 \mu \mathrm{l}$ for each slide. A coverslip was placed on the preparation to distribute the enzyme evenly. Incubation with the enzyme was carried out overnight at $37^{\circ} \mathrm{C}$ in a moist chamber. After the treatment slides were washed in tap water and stained with 5 per cent Giemsa in distilled water. Control preparations were treated with the incubation buffer under the same experimental conditions.

\section{RESULTS}

The restriction endonucleases, Alu I, Hae III, Mbo I and Hpa II extensively digested all euchromatic regions and only partially altered the heterochromatic ones. Differences of banding pattern between Anopheles atroparvus and A. labranchiae were restricted to the sex chromosome heterochromatin (figs 1, 2, 3, 4). The digestion pattern of each enzyme did not present significant differences from the one produced by the other enzymes tested.

In $A$. atroparvus, the proximal and terminal regions of the $\mathrm{X}$ and $\mathrm{Y}$ long arms were resistant to RE digestion and stained darkly with Giemsa (figs $1 ; 2(\mathrm{a}, \mathrm{c}, \mathrm{e}, \mathrm{g}) ; 3(\mathrm{a}) ; 4)$. An intercalary band, sometimes distinct in two subunits, was observed after digestion with Hae III, Mbo I and, less clearly, with Alu I and Hpa II (figs 2(a, g); 4(c, e). In some early metaphase stages the proximal band was resolyed in two smaller adjacent bands (fig.
A. atroparvus

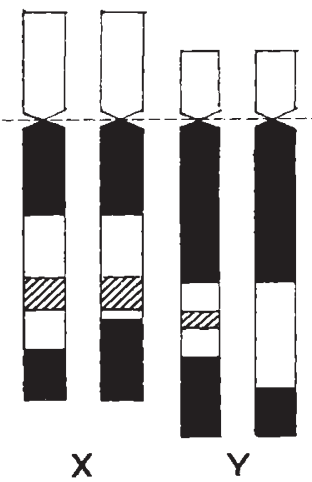

A. Iabranchiae

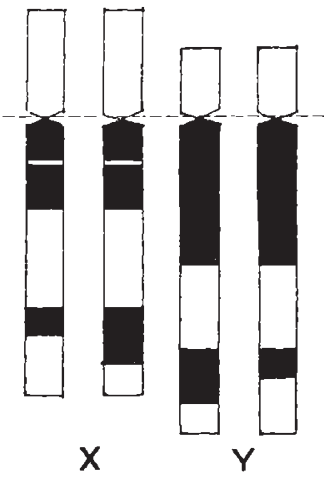

Figure 1 Main features and differences of the sex chromosome banding pattern in Anopheles atroparvus and Anopheles labranchiae after treatment with the restriction enzymes, Alu I, Hae III, Mbo I and Hpa II. Idiograms represent the patterns and band variants most frequently observed on the $\mathrm{X}$ and $\mathrm{Y}$ chromosomes. However, within each species, patterns found on the $\mathrm{X}$ are also shared by the $\mathrm{Y}$ and vice versa. Dark areas are the constant RE resistant bands, shaded areas are less conspicuous and variable bands. Presence of two proximal bands is only shown on the $\mathrm{X}$ chromosome of $A$. labranchiae, where the bands are very often distinct, while on the $\mathrm{Y}$ and on the sex chromosomes of $\boldsymbol{A}$. atroparvus proximal bands are usually fused together.

$2(\mathrm{~g}))$. The terminal band did not include the telomeric tip; however this differentiation was not appreciable in condensed metaphase chromosomes. The amount of heterochromatin resistant to $R E$ treatment varied from 50 to 80 per cent of the $\mathrm{X}-\mathrm{Y}$ long arm $($ mean $=63.1)$. This quantitative variation was due to a high level of heterochromatin polymorphism (figs 2(a, c,e,g); $4(\mathrm{a}, \mathrm{c}, \mathrm{e}))$. Two size variants of the proximal band and two of the terminal band were most frequently observed (fig. 1). These variants were shared by both sex chromosomes. However, the large variant of the proximal band was more frequent on the $\mathrm{Y}$ chromosome than on the $\mathrm{X}$ (figs $2(\mathrm{c}, \mathrm{e}, \mathrm{g}) ; 4(\mathrm{a})$ ). Of 11 males scored, eight had a larger proximal band on the $\mathrm{Y}$ chromosome. Variants of the distal band were equally distributed in the two sex chromosomes. The idiogram in fig. 1 shows the banding patterns most frequently observed on the $\mathrm{X}$ and $\mathrm{Y}$ chromosomes. Variants with extensive loss of digested heterochromatin (intercalary pale region) were also observed (fig. 4(e)).

In $A$. labranchiae, the $\mathrm{X}-\mathrm{Y}$ banding pattern produced by Alu I, Mbo I, Hae III and Hpa II was different from the pattern of $A$. atroparvus in terms of band position and amount of heterochromatin digested by the enzymes (fig. 1). This pattern was 

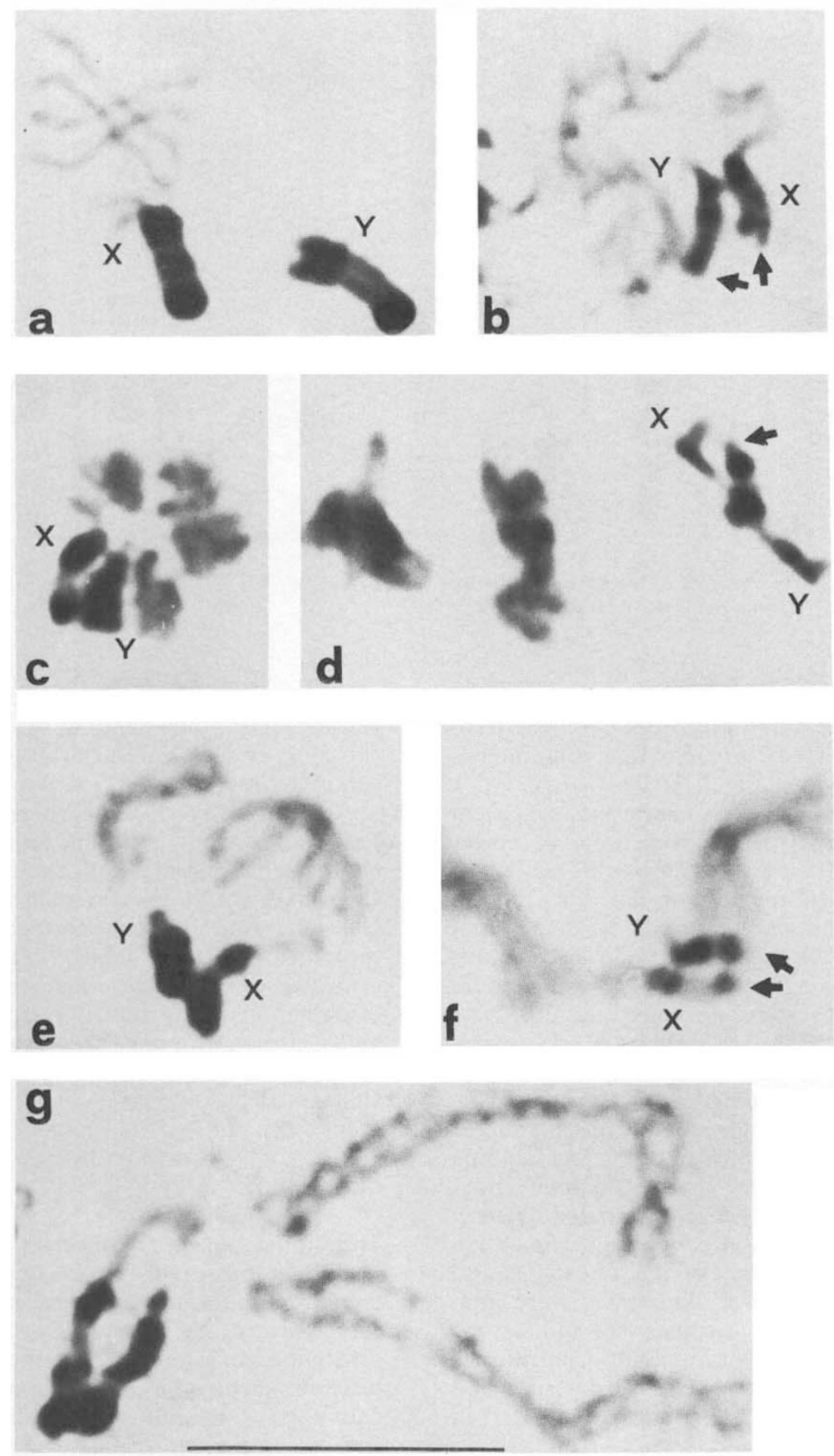

Figure 2 Banding pattern produced by Alu I (a, b), Hae III (c, d) and Mbo I (e, f, g) on the mitotic chromosomes of A. atroparvus $(\mathrm{a}, \mathrm{c}, \mathrm{e}, \mathrm{g})$ and $A$. labranchiae $(\mathrm{b}, \mathrm{d}, \mathrm{f})$ male larvae: $(\mathrm{e})$ and $(\mathrm{g})$ are different mitotic stages from the same individual. Arrows point to the pale telomeric region of the sex chromosome long arm altered by the three enzymes in $A$. labranchiae. Bar represents $10 \mu \mathrm{m}$. 

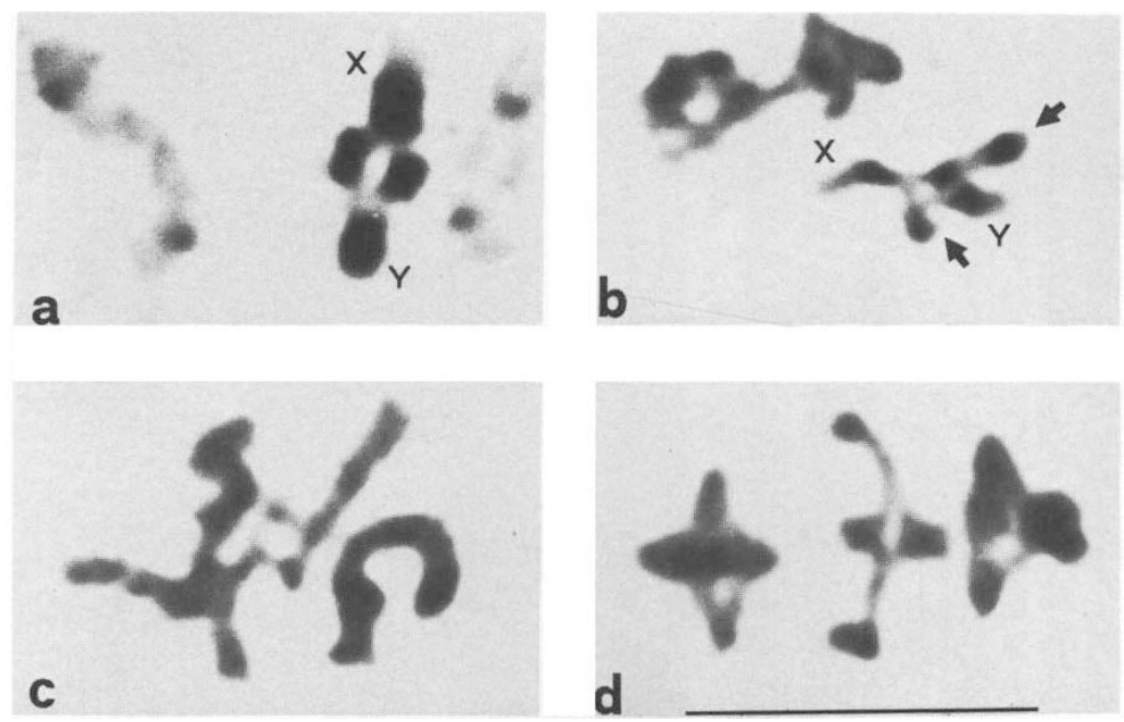

Figure 3 Banding pattern produced by the isoschizomers Hpa II (a, b) and Msp I (c, d) on meiotic chromosomes of A. atroparvus (right) and A. labranchiae (left). Bar represents $10 \mu \mathrm{m}$.

characterized by two proximal and one distal bands and by the digestion of the terminal 10-15 per cent of the heterochromatic long arm, including the telomere (figs $2(\mathrm{~b}, \mathrm{~d}, \mathrm{f}) ; 3(\mathrm{~b}) ; 4(\mathrm{~b}, \mathrm{~d}, \mathrm{f})$ ). A faint intercalary band, less sharp and consistent than in $\boldsymbol{A}$. atroparvus, was sometimes observed. The amount of RE resistant heterochromatin was significantly lower (mean $=48$ per cent) than in $A$. atroparvus and varied from 25 to 63 per cent of the long arm. Both proximal and distal bands were found polymorphic (fig. 1). Variants were common to both sex chromosomes (figs $2(\mathrm{~b}, \mathrm{~d}, \mathrm{f}$ ); $3(\mathrm{~b}) ; 4(\mathrm{~b}, \mathrm{~d}, \mathrm{f}))$. However, like in $A$. atroparvus, the $\mathrm{Y}$ chromosome carried the largest variant of the proximal band more frequently than the $X$ (fig. 2(b, d, f)). Patterns most frequently observed in $\boldsymbol{A}$. labranchiae are represented in fig. 1 . The banding patterns of the two sibling species did not overlap, except in the infrequent case of terminal deletion in the X-Y long arm in A. labranchiae (fig. 4(b)).

The euchromatic arms of the autosomes and the short arm of the sex chromosomes, were completely digested by the four enzymes and stained faintly with Giemsa in both species. Centromeric regions were less sensitive to enzyme digestion and stained darker than the arms, particularly in meiosis.

Msp I produced almost no banding in either species (fig. 3(c, d)). In mitosis, the sex chromosomes sometimes showed a hint of differentiation similar to the one produced by the other four enzymes. Most frequently, and always in meiotic chromosomes, no banding was observed and chromosomes appeared darkly stained as in the control slides.

Quantitative heterochromatin differences between the $\mathrm{X}$ and $\mathrm{Y}$ chromosomes did not inhibit chromosome pairing and chiasmata formation. Chiasmata within the sex pair were observed in males carrying different heterochromatic variants (proximal and distal bands) on the $\mathrm{X}$ and $\mathrm{Y}$ long arms (fig. 5(a)). In these heterozygous males, recombination within the $\mathrm{X}-\mathrm{Y}$ pair was visualized by the presence of sex chromosomes with heteromorphic chromatids in metaphase and anaphase II stages (fig. $5(\mathrm{~b}, \mathrm{c}, \mathrm{d})$ ).

\section{DISCUSSION}

The sibling species Anopheles labranchiae and Anopheles atroparvus possess typical maculipennis type sex chromosomes, with submetacentric $X$ and subtelocentric $\mathrm{Y}$. The two species have similar distribution of C-positive heterochromatin but are discriminated by the Q-banding pattern of the X-Y pair and by the differential response of the $Y$ chromosome short arm after acid-alkaline treatment followed by Coriphosphine $\mathrm{O}$ staining (Mezzanotte and Ferrucci, 1978; Mezzanotte et al., 1979). Structural chromosome differences between the two species were revealed by digestion with 

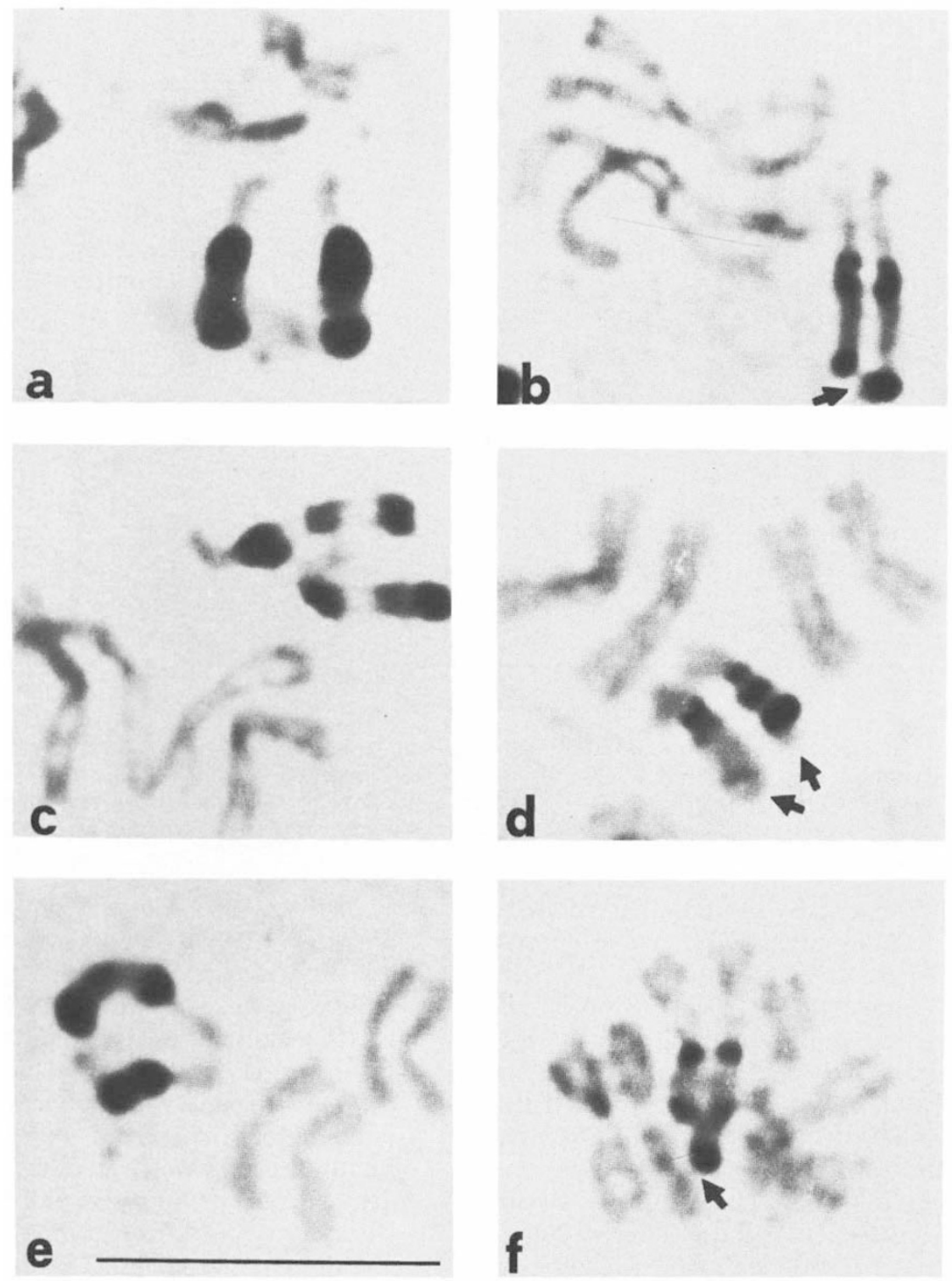

Figure 4 Intraspecific heterochromatic polymorphism in A. atroparvus (left) and $A$. labranchiae (right) revealed by digestion with Alu I (a, b), Hae III (c, d) and Mbo I (e, f). Mitoses from females heterozygous for different heterochromatic variants. Arrows point to the pale telomeric region of the $\mathrm{X}$ long arm altered by the three enzymes in $A$. labranchiae. Bar represents $10 \mu \mathrm{m}$.

four restriction endonucleases (Alu I, Hae III, Mbo I and Hpa II). The banding pattern produced by these enzymes on the sex chromosomes of the two species was distinctive in terms of localization of bands and amount of digested and undigested heterochromatin. A larger amount of heterochromatic material was altered in A. labranchiae, as compared with $A$. atroparvus, suggesting the presence, in the former species, of a higher number of DNA target sequences available for enzyme cleavage. Differences of banding pattern between the two species mainly concerned digestion of the terminal 10-15 per cent of the X-Y long arm in $A$. labranchiae, while the corresponding region in $A$. atroparvus was not altered by the four enzymes. These results confirmed that chromosome divergence between the two sibling species has involved changes, and probably rearrangements, in the heterochromatin DNA of the sex chromosomes, while the structural organization of the autosomes 

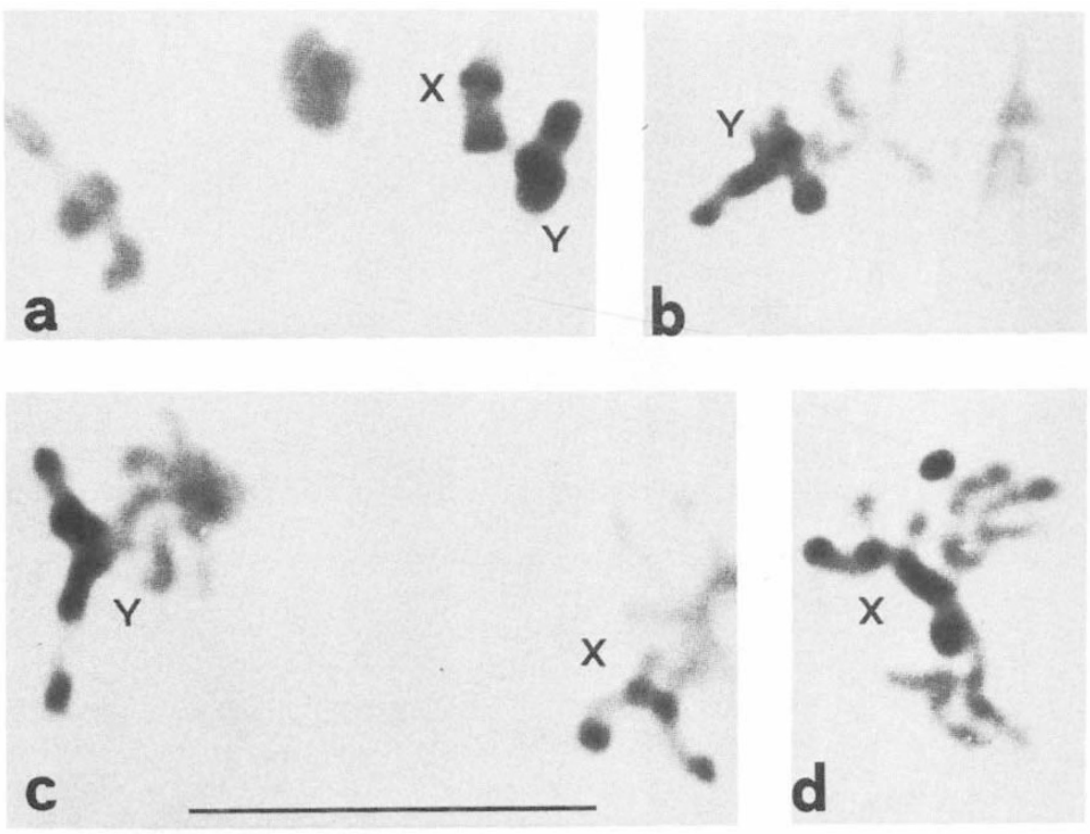

Figure 5 Meiotic chromosomes, digested with Hae III, from testes of $\boldsymbol{A}$. atroparvus larva. (a): metaphase I with sex chromosomes carrying different heterochromatic variants; (b) and (c) anaphase II stages in which the sex chromosomes have heteromorphic chromatids with different banding patterns, as a consequence of a proximal crossing-over; (d) anaphase II showing the result of an interstitial crossing-over, the chromatids of each sex chromosome carry the two variants of the distal band. Bar represents $10 \mu \mathrm{m}$.

has not been dramatically modified, as suggested by the banding homologies of polytene chromosomes (Tiepolo et al., 1974).

The sex chromosome heterochromatin of these sibling species was only partly digested by REs, resembling, particularly in $A$. atroparvus, the longitudinal differentiation generated by strong alkaline denaturation $(\mathrm{NaOH})$, i.e., proximal and distal C-positive bands on the long arm (Tiepolo et al., 1975; Marchi, personal observation). Besides confirming the presence of these different heterochromatin types, digestion with REs revealed additional heterogeneity within the heterochromatic arm of the sex chromosomes (table 1). In $A$.

Table 1 Heterochromatin heterogeneity revealed by standard C- and Q-banding techniques and by digestion with restriction enzymes. Ret refers to the RE resistant heterochromatin

\begin{tabular}{llllllll}
\hline Species & \multicolumn{3}{l}{ A. atroparvus } & & \multicolumn{3}{c}{ A. labranchiae } \\
\cline { 2 - 4 } \cline { 5 - 7 } Banding & C & Q & RE & & C & Q & RE \\
\hline Heterochr. & + & + & + & & + & - & + \\
types & + & + & - & + & - & - \\
& - & - & + & - & - & + \\
& - & - & - & & - & - & - \\
\hline
\end{tabular}

atroparvus, the C-positive regions of the long arm are also bright fluorescent with quinacrine (Tiepolo et al., 1975). These regions are resistant to RE digestion. However, the RE resistant heterochromatin includes also $\mathrm{C}$ and $\mathrm{Q}$-negative regions. On the other hand, the C-positive heterochromatin of A. labranchiae, which fluoresces dull with quinacrine (Mezzanotte and Ferrucci, 1978), is not totally resistant to $\mathrm{RE}$ digestion. While correspondence between C-positive and RE resistant heterochromatin exists for the proximal bands, the terminal region, although C-positive, is altered by the three enzymes. These results confirm the usefulness of $\mathrm{RE}$ digestion in uncovering structural differences within heterochromatic regions.

Intraspecific heterochromatin polymorphism, undetected with standard banding techniques, was common in both Anopheles species after digestion with REs. Heterochromatin variation was quite high even in the highly inbred colony of $A$. atroparvus, although lower than in the field populations of A. labranchiae. This situation is quite different from that found in species of the Anopheles gambiae complex using fluorescent staining: the sex chromosomes of most laboratory populations were monomorphic and natural populations only possessed one or two heterochromatic variants 
(Bonaccorsi et al., 1980). It would be interesting to test whether or not additional polymorphism can be revealed also in these species using restriction enzymes. Variants in $A$. labranchiae and $A$. atroparvus were characterized by changes in the relative amount of digested and undigested heterochromatin, usually with little or no changes of total chromosome length; extensive loss of heterochromatin was observed in the two species only in a few cases. The $\mathrm{X}$ and $\mathrm{Y}$ chromosomes shared the same heterochromatic variants. However, difference in the frequency of the proximal band variants were observed between $X$ and $Y$. The proximal band was usually larger in the $\mathrm{Y}$ than in the $\mathrm{X}$ chromosome, possibly due to low recombination frequency in the proximal region. This hypothesis is supported by data on chiasmata frequency in $A$. atroparvus males which indicate a low frequency of proximal chiasmata $(0 \cdot 03)$ as compared with interstitial chiasmata $(0 \cdot 28)$ (Jayakar et al., 1982).

High heterogeneity and variability are characteristic features of heterochromatin. In the Anopheles genus the heteromorphic sex chromosomes are partly or totally heterochromatic (White, 1980) and intraspecific polymorphism of heterochromatic regions is quite common (Baimai and Traikpavasin, 1987; Bonaccorsi et al., 1980; Vasantha et al., 1982). Many, if not most, characteristics of constitutive heterochromatin are linked to the presence of high concentrations of satellite DNAs in this type of chromatin. In Anopheles stephensi, satellite DNA has been localized in the heterochromatic arms of the $\mathrm{X}$ and $\mathrm{Y}$ chromosomes by in situ hybridization (Redfern, 1981). Likewise, the heterochromatic, high polymorphic and RE-resistant heterochromatin of $A$. labranchiae and $A$. atroparvus may contain satellite DNAs which do not possess cleavage sequences of the REs tested. Intraspecific and interspecific variation in the sequence and abundance of highly repetitive DNA is also widespread in nature and has been reported in several mosquito species of the genus Aedes (McLain et al., 1986; McLain et al., 1987). The occurrence of such high polymorphism would imply that heterochromatin is not essential in basic cell functions and heterochromatic variations may be without any selective advantage. On the other hand, experimental observations support the adaptive significance of heterochromatin in recombination (John, 1981) and cell growth (Macgregor and Sessions, 1986). Although the evolutionary significance of these variations and, in general, of heterochromatin and associated DNA is still debated, they probably play an important role in evolution producing "most of the changes in chromosome size and structure during divergence of species" (Flavell, 1982), ultimately reinforcing reproductive isolation of populations. Heterochromatin variants in $A$. labranchiae and $A$. atroparvus probably arise quite frequently and spread in the populations by drift phenoman. Karyotypic divergence in the two sibling species could have derived from a common ancestor by fixation of different heterochromatic variants with progressive decrease of chromosome homology.

Differently from the other enzymes, Msp I did not produce any banding pattern on the chromosomes of A. labranchiae and A. atroparvus. Msp I and Hpa II are isoschizomers which cleave the same sequence, CCGG. Their activity is inhibited by methylation of the external (Msp I) or internal (Hpa II) cytosine (Maniatis et al., 1982). The result obtained in the two sibling species would suggest that selective methylation of the external cytosine and consequent inhibition of the Msp I digestion occurs in euchromatic and heterochromatic regions. However, differential access of the enzymes to the target sequences could also play a role in the resulting pattern. Bianchi and coworkers (1986) obtained quite different pattern on a cell line of the mosquito, Aedes albopictus, indicating lack of methylation in most CCGG sequences. In another mosquito, Culiseta longiareolat , both enzymes produced the same banding pattern on larval brain and gonadal cells, with digestion of the euchromatic regions but not of the heterochromatic ones (Marchi and Mezzanotte, 1988). These results suggest that different levels of methylation, or different chromatin organization, exist in different species of the Culicidae family.

\section{REFERENCES}

BAIMAI, V. AND TRAIPAKVASIN, A. 1987. Intraspecific variation in the sex heterochromatin of species B of the Anopheles dirus complex in Thailand. Genome, 29, 401-404.

BIANCHI, N. O., VIDAL-RIOJA, L. AND CLEAVER, J. E. 1986. Direct visualization of the sites of DNA methylation in human, and mosquito chromosomes. Chromosoma, 94, $362-366$.

BONACCORSI, S., SANTINI, G., GATTI, M., PIMPINELLI, S. AND COLUZZI, M. 1980. Intraspecific polymorphism of sex chromosome heterochromatin in two species of the Anopheles gambiae complex. Chromosoma, 76, 57-64.

BULTMANN, H. AND MEZZANOTTE, R, 1987. Characterization and origin of extrachromosomal DNA granules in Sarcophaga bullata. J. Cell Sci., 88, 327-334.

FLAVELL, R. B. 1982. Sequence amplification, deletion and rearrangement: major sources of variation during species divergence. In Dover, G. A. and Flavell, R. B. (eds) Genome Evolution, Academic Press, London, pp. 301-324. 
FRACCARO, M., LAUDANI, U., MARCHI, A. AND TIEPOLO, L. 1976. Karyotype, DNA replication and origin of sex chromosomes in Anopheles atroparvus. Chromosoma, 55, 27-36.

FRIZZI, G. 1947. Cromosomi salivari in Anopheles maculipennis. Scientia Genet., 3, 67-79.

GOSALVEZ, J., BELLA, J. L., LOPEZ-FERNANDEZ, C. AND MEZZANOTTE, R. 1987. Correlation between constitutive heterochromatin and restriction enzyme resistant chromatin in Arcyptera tornosi (Orthoptera). Heredity, 59, 173-180.

JAYAKAR, S. D., LAUDANI, U. AND MARCHI, A. 1982. An analysis of chiasmata frequencies in Anopheles atroparvus. Rend. Sem. Fac. Sci. Univ. Cagliari, 52, 127-133.

JOHN, B. 1981. Heterochromatin variation in natural populations. In Bennet, M. D., Bobrow, M. and Hewitt, G. M. (eds) Chromosome Today, 7, Allen \& Unwin, London, pp. 128-137.

JOST, E. AND MAMELI, M. 1972. DNA content in nine species of Nematocera with special reference to the sibling species of the Anopheles maculipennis group and the Culex pipiens group. Chromosoma, 37, 201-208.

KITZMILlER, J. B. 1967. Mosquito cytogenetics. In Wright, J. W. and Pal, R. (eds) Genetics of Insect Vectors of Diseases, Elsevier, Amsterdam, pp. 133-150.

LOPEZ-FERNANDEZ, C., GOSALVEZ, J., SUJA, J. A. AND MEZZANOTTE, R. 1988. Restriction endonuclease digestion of meiotic and mitotic chromosomes in Pyrgomorpha conica (Orthoptera: Pyrgomorphidae). Genome, 30, 621-626.

MACGREGOR, H. C. AND SESSIONS, S. K. 1986. The biological significance of variation in satellite DNA and heterochromatin in newts of the genus Triturus: an evolutionary perspective. Phil. Trans. R. Soc. Lond., B312, 243-260.

MANIATIS, T., FRITSCH, E. F. AND SAMBROOK, J. 1982. Molecular Cloning. Cold Spring Harbor Laboratory, New York, p. 453.

MARCHI, A. AND MEZZANOTTE, R. 1988. Restriction endonuclease digestion and chromosome banding in the mosquito, Culiseta longiareolata (Diptera: Culicidae). Heredity, 60, 21-26.

MCLAIN, D. K., RAI, K. S. AND FRASER, M. J. 1986. Intraspecific variation in the abundance of highly repeated DNA sequences in the Aedes scutellaris subgroup. Ann. Ent. Soc. Amer., 79, 784-791.

MCLAIN, D. K., RAI, K. S. AND FRASER, M. J. 1987. Intraspecific and interspecific variation in the sequence and abundance of highly repeated DNA among mosquitoes of the Aedes albopictus subgroup. Heredity, 58, 373-381.
MEZZANOTTE, R. 1986. The selective digestion of polytene and mitotic chromosomes of Drosophila melanogaster by the Alu I and Hae III restriction endonucleases. Chromosoma, 93, 249-255.

MEZZANOTTE, R. AND FERRUCCI, L. 1978. Recognition of the sibling species Anopheles atroparvus (Van Thiel) and Anopheles labranchiae (Falleroni) (Diptera: Culicidae) on the basis of $\mathrm{Q}$ and $\mathrm{C}$ banding. Monitore Zool. Ital., 12, 211-218.

MAZZANOTTE, R., FERRUCCI, L. AND MARCHI, A. 1979. Y chromosome in the sibling species Anopheles atroparvus (Van Thiel, 1927) and A. labranchiae (Falleroni, 1926) (Diptera: Culicidae): differential behaviour of the short arm after acid-alkaine treatment and Coriphosphine-O staining. Experientia, 35, 312-313.

MEZZANOTTE, R., FERRUCCI, L., VANNI, R. AND BIANCHI, U. 1983. Selective digestion of human metaphase chromosomes by Alu I restriction endonuclease. J. Histochem. Cytochem., 32, 553-556.

MEZZANOTTE, R. AND MARCHI, A. 1987. In situ digestion of Drosophila virilus polytene chromosomes by Alu I and Hae III restriction endonucleases. Genome, 29, 630-634.

MILLER, D. A., CHOI, J. C. AND MILLER, J. O. 1983. Chromosome localization of highly repetitive human DNAs and amplified ribosomal DNA with restriction enzymes. Science, 219, 395-397.

REDFER N, C. P. F. 1981. Satellite DNA of Anopheles stephensi Liston (Diptera: Culicidae). Chromosoma, 82, 561-581.

TIEPOLO, L., DIAZ, G. AND LAUDANI, U. 1974. Differential DNA synthesis in homologous regions of hybrid polytenic chromosomes (Anopheles atroparvus $\times$ Anopheles labranchiae). Chromosoma, 45, 81-89.

TIEPOLO, L., FRACCARO, M., LAUDANI, U. AND DIAZ, G. 1975. Homologous bands on the long arms of the $X$ and $Y$ chromosomes of Anopheles atroparvus. Chromosoma, 49, 371-374.

VASANTHA, K., SUBBARAO, S. K., ADAK, T. AND SHARMA, V. P. 1982. Karyotipic variations in Anopheles culicifacies complex. Indian J. Malariol., 19, 27-32.

WHITE, G. B. 1980. Academic and applied aspects of mosquito cytogenetics. In Blackman, R. L., Hewitt, G. M. and Ashburner, M. (eds) Insect Cytogenetics, Blackwell Sci. Publ., Oxford, pp. 245-274. 